hospital whom they find in the street in a similar state weeks, or even days, later; those who have been released from Special Hospitals and who re-offend-this last they find a particularly sore point. Examples such as these usually lead to lively discussion about the interpretation of the Mental Health Act and human rights. How we decide someone is well is a frequent question. It seems important to say that we too suffer frustration when we can see the way someone's life could be less distressing and yet are unable to do anything about it unless they either agree or fulfil the criteria the law demands. It seems our inability to act in these cases is often seen as stubbornness and awkwardness until this is explained. Other areas covered include dealing with personality disorder, drug addiction, alcoholism and situational crisis. Our move into the community has meant a decrease in in-patient beds and, therefore, stricter criteria for admission. Case illustrations of patients who have been more usefully helped by avoiding admission are discussed.

\section{Summary}

The importance of these seminars seems to be in establishing communications, in correcting wrong impressions, in giving some practical guidelines in dealing with patients and in explaining how we are attempting to make psychiatry more acceptable. In the course of doing this, the sharing of anxieties and frustrations involved in dealing with the mentally disturbed person in the community does seem to correct misconceptions on both sides.
Recently this educative process has become a two-way venture. The local psychiatrists have had a useful seminar from the police sergeant in whose 'patch' our hospital lies. We learnt of the difficulties in policing such an area, the restrictions on manpower and the difficulties the police have in encouraging people to seek medical help-bound as they are both by our confidentiality and theirs. That the police themselves have strict rules about confidentiality is frequently overlooked.

It does seem that such interchanges are already showing signs of strengthening co-operation and understanding between ourselves and the local police and would seem to illustrate, in small part, what community psychiatry is about.

\section{REFERENCES}

'Kenyon, F. E. (1968) Psychiatric Emergencies and the Law. Bristol: John Wright.

${ }^{2}$ Kelleher, M. J. \& Copeland, J. R. M. (1972) Compulsory psychiatric admission by the police. Medicine, Science and the Law, July $1972,220-4$.

${ }^{3}$ Sims, A. C. P. \& Symonds, R. L. (1975) Psychiatric referrals from the police. British Journal of Psychiatry, 127, 171-8.

'Janus, S. S., Bess, B. E. et al (1980) Training police officers to distinguish mental illness. American Journal of Psychiatry, 137, 228-9.

'Cooper, C. L., Davidson, M. J. et al (1982) Stress in the police service. Journal of Occupational Medicine, 2A, 30-36.

\title{
Community Care: The Sham Behind the Slogan
}

\author{
National SChIzophrenia Fellowship
}

The following letter and statement were published on 28 February 1984 and were widely circulated to influential bodies.

\section{Dear Colleagues}

Hospital closures and community care

I enclose a statement drawn up by the National Schizophrenia Fellowship in consultation with the Richmond Fellowship. It also has the support of the Psychiatric Rehabilitation Association, the St Mungo Community Trust, and the Salvation Army. Our aim is to bring to the notice of those with public responsibility and of the Press the deep concern felt by a number of national voluntary organizations involved with mental illness.

None of us want patients to be in psychiatric hospitals on a long-term basis if this is not necessary. We would wholeheartedly endorse the Government policy of closing old, rundown mental institutions if a range of appropriate and adequate services is made available to mental patients elsewhere before they shut down. We are against any policy which accentuates the social isolation and stigma experienced by those who suffer from mental illness.

But the drive, at all costs, to move mental patients out of hospital and into the community is at present leading to disastrous human and social problems. All our first-hand experience shows that there is widespread failure to provide adequate aftercare or to grant-aid those for whom this care is available. We are also convinced that the number of those suffering from severe mental illness who are very seriously disabled has been under-estimated. The needs of those requiring ongoing support of various kinds, including suitable support for the families, must be far more accurately assessed if adequate provision is to be made for them. Some may need lifelong care of a kind which at present only the psychiatric hospital provides.

Current plans will close large mental hospitals before 
adequate alternative provision exists for the patients. Current discharge polices often send patients out into the community (at times back onto the streets) so rapidly that no appropriate arrangements for aftercare can possibly be made. This causes much suffering not only for those directly involved, but also for their families. The move to speed up the discharge process is causing great anxiety, not only to relatives, but also to those in our organizations who work in the field, and who consider the present situation totally unsatisfactory.

We are convinced that these policies need review as a matter of the utmost urgency, and that new, innovative, but realistic plans should be made, based on a far more searching assessment of the numbers of those in need, the degree and nature of their problems or disabilities, the kind of alternative service needed, the time it will take to provide the service, and the agency which will provide it.

We should be grateful for your comments. I should add that we have consulted the Church Army, who have also seen our statement, and they have similar difficulties in working with those patients discharged from mental hospitals into their large hostels.

Yours sincerely, JOYCE MAJOR

Chairman

\section{Statement agreed by National Schizophrenia Fellowship and Richmond Fellowship}

1. Those suffering from mental illness have varying needs, depending on their own wishes and the course of their illness. The following statement, drawn up by the National Schizophrenia Fellowship, in consultation with other organizations, concentrates on the problems of people suffering from schizophrenia, a very common illness, which affects one in every hundred people. More patients are in hospital because of schizophrenia than as a result of any other medical or surgical condition.

2. Any plan to close mental hospitals directly affects both those afflicted and those who care for them, and this joint statement is made in the first instance in response to the planned closure of Banstead, Norton, Friern, Claybury, Long Grove and West Park hospitals, just outside London. But it applies to many other areas.

3. Of those affected by schizophrenia, often young people, 20-25 per cent are likely to recover rapidly and will probably maintain themselves throughout their lives with little further help. Another 50-60 per cent may well be able to live outside hospital, but will need support of many different kinds. The remaining 20-25 per cent require so much care, probably on a long-term basis, that hospitals are at present the only places able to look after them.

4. Government policies outlined in the 1981 Green Paper, Care in the Community, and the Government statement on
12 July $1983^{*}$, that it seemed likely that many large isolated psychiatric hospitals will prove redundant, will almost certainly force many mentally ill patients into the community without adequate care. It should not be forgotten that there is no certain cure for severe mental illness, and in some cases lifelong disablement results, to a greater or lesser degree, despite modern drug treatments.

5. We are agreed:

(i) That services for the mentally ill outside hospital are totally inadequate in many parts of the country. The majority of mental patients who have been seriously ill are accepted on discharge into their homes by relatives, who then try to cope with sometimes bizarre, violent or potentially suicidal situations with little or no support. This is what care in the community usually means. Many former patients without families, or whose families reach breaking point, get no care at all, and end up in prison or mental hospital, as vagrants, or commit suicide.

(ii) That the provision of hostels, group homes, etc. is insufficient, and where hostels exist they are often underutilized because no public authority will pay the fees.

(iii) That it is often very difficult indeed to obtain hospital admission for people who, without doubt, are in desperate need of in-patient treatment.

6. We therefore urge the Government:

I (i) To give shelter and care to those most mentally disabled in the only places properly equipped to provide itour psychiatric hospitals - unless or until other adequate alternatives actually exist. Though local health and social services authorities are legally obliged to provide aftercare, what this should include has not yet been identified in statutory terms.

(ii) To reject the idea that the life of a long-stay mental hospital patient is necessarily worse than life as a homeless vagrant, which is for many the only alternative. The patient does not choose to leave the asylum provided by a psychiatric hospital, in many cases, but is compelled to leave.

(iii) To give backing to staff manning this essential service both with adequate resources, and by in-service training, so that morale, now lowered by incessant threats of closures and by a running fire of ill-informed criticism, can be restored.

(iv) To ask psychiatrists to modify the widespread Open Door Policy, not by returning to the past, when every mental hospital ward was locked, but by recognizing that some secure accommodation is required in most health districts for the relatively few people who need it. We believe present policies often lead to prison sentences for the mentally ill, and to a refusal by the hospitals to admit those most in need of treatment. We do not think the planned provision of regional secure units will fully solve this problem.

"Lord Glenarthur, Minister at the DHSS with special responsibility for mental health matters, replying to a Parliamentary Question from Lord Mottistone. 